\title{
Inflammatory bronchopulmonary response of preterm infants with microbial colonisation of the airways at birth
}

\author{
Peter Groneck, Bettina Goetze-Speer, Christian P Speer
}

\begin{abstract}
The inflammatory indicators in the tracheobronchial aspirate (TA) of 81 ventilated preterm infants with microbial colonisation of the airways and in noncolonised neonates were analysed on the first day of life. TA was assessed for chemotactic activity, neutrophil cell count, and concentrations of leukotriene $B_{4}, C 5 a$, interleukin-1, interleukin-8, elastase- $\alpha_{1}$ proteinase inhibitor, free elastase and albumin. Concentrations of mediators were related to concentrations of the secretory component of IgA.
\end{abstract}

The infants' gestational age was mean (SD) $27.9(2.0)$ weeks, birthweight 945 (179) g. In 12 infants $(15 \%)$ microbial colonisation of the airways was present (Ureaplasma urealyticum $n=7$; bacteria $\mathbf{n}=5)$. Compared with non-colonised neonates $(n=69)$, chemotactic activity, neutrophil count, and concentrations of interleukin-1, leukotriene $B_{4}$ and elastase$\alpha_{1}$-proteinase inhibitor were significantly higher in the colonised group. The difference was most pronounced for IL-1 concentrations, both with and without correction for secretory component. There was also a trend towards increased concentrations of interleukin-8 in the latter group. There were no differences for concentrations of $\mathbf{C 5 a}$ and albumin in the TA of both groups.

It is concluded that airway colonisation with $U$ urealyticum or bacteria at birth is associated with a clinically relevant bronchopulmonary inflammatory response. Increased concentrations of interleukin-1 in TA on the first day of life may be a marker of perinatal colonisation of the airways.

(Arch Dis Child 1996; 74: F51-F55)

Pediatrics, Children's Hospital of the City of Cologne, Germany P Groneck

Department of

Neonatology,

University Children's

Hospital, Tuebingen,

Germany

B Goetze-Speer

C P Speer

Correspondence to: Dr P Groneck, Department of Pediatrics, Children's Hospital of the City of Cologne, Amsterdamer $\mathrm{St}$ 59, D-50735 Cologne, Germany.

Accepted 28 September 1995
Additionally, in perinatal infections bacteria are often isolated from different sites of the neonate, and a positive culture in the airways might reflect simple aspiration of contaminated amniotic fluid.

Perinatal infections with Ureaplasma urealyticum have been associated with prolonged respiratory dependency and the development of bronchopulmonary dysplasia. ${ }^{23}$ However, the clinical relevance of $U$ urealyticum detectable in airway fluids for the development of subsequent lung disease has been questioned. ${ }^{4}$ Growth of ureaplasma in tracheobronchial aspirates may also reflect aspiration of amniotic fluid. A study of the inflammatory response of the airways would permit a description of the interactions between microorganisms and host immune factors.

The response of neonatal airways to microbial colonisation has only partly been characterised. Increased numbers of neutrophils have been found in the tracheobronchial aspirates of newborns with perinatal infection of the airways. ${ }^{5-7}$ Nearly all of these cells are of fetal origin. ${ }^{8}$ Additionally, increased concentrations of interleukin- 6 are present in the respiratory fluids of newborns who have sustained prolonged rupture of membranes. ${ }^{9}$ Increased leucocyte elastase activity in the tracheal aspirate at birth has been associated with the development of neonatal pulmonary emphysema. ${ }^{10}$

In order to characterise the inflammatory mechanisms involved following perinatal colonisation of the airways, inflammatory indicators in tracheobronchial aspirate were prospectively analysed in infants with positive tracheal cultures for bacterial or $U$ urealyticum, and compared with those of infants without colonisation of the airways.

\section{Methods}

Eighty five preterm infants weighing $<1200 \mathrm{~g}$ were consecutively admitted to the neonatal intensive care units of the Children's Hospital, Cologne, and the Perinatal Center at the Women's Hospital, Cologne-Holweide, during two periods from 18 June 1991 to 15 October 1992, and from 26 April 1993 to 16 August 1993. Eighty one of the infants had been intubated immediately after birth and were included in this study; 70 of these 81 infants were born by caesarean section and 11 by vaginal delivery.

TA was collected for microbiological cultures including $U$ urealyticum within the first hour. No tests for the presence of Chlamydia trachomatis or cultures for virus were done. Primary care and subsequent nursery procedures during the first 14 days were performed 
with sterile gloves. Intravenous antibiotics (meziocillin and gentamycin) were started in 79 of the infants within the first 10 days of obtaining tracheal cultures. All infants with respiratory distress syndrome (RDS) were treated with natural porcine surfactant. ${ }^{11} \mathrm{RDS}$ was diagnosed from a typical chest radiograph, oxygen dependency, and clinical signs of respiratory distress. Bronchopulmonary dysplasia (BPD) was defined as oxygen dependency and radiological abnormalities on day 28 .

To characterise the inflammatory response, the chemotactic activity of TA, neutrophil count, and concentrations of inflammatory mediators were evaluated in infants with tracheal cultures positive for bacteria or Ureaplasma, and in infants with no growth of these micro-organisms in TA.

When aspiration of the airways was indicated clinically, tracheobronchial aspirate was collected three times during the first 24 hours of life. Tracheobronchial aspiration was performed by instillation of $0.5 \mathrm{ml} 0.9 \% \mathrm{NaCl}$ into the endotracheal tube. Suction catheters were inserted slightly beyond the distal tip of the tube; lung and airway secretions were suctioned and collected in sterile specimen traps (Vigon, Ecouen, France). TA was diluted with $0.9 \%$ saline to a total volume of $0.5 \mathrm{ml}$, centrifuged at $3000 \mathrm{rpm}$ for 5 minutes, and cell free supernatant fluids were frozen at $-30^{\circ} \mathrm{C}$ for later assays. Over 24 hours, one specimen was obtained in each eight hour period. Immediately before the biochemical analysis of TA, the three samples from one day were pooled.

Specimens for $U$ urealyticum were obtained during suctioning of the trachea within one hour of birth. The suction catheter was attached to a sterile mucus trap. For transport to the laboratory, the specimens were then put into a Ureaplasma culture medium. Specimens were inoculated onto A-7 Ureaplasma differential agar plates. Specimens were also inoculated into a fluid medium (U-9). The inoculated plates and tubes were incubated anaerobically for five days and were observed for growth every 24-48 hours. Ureaplasma was identified by colonial morphology (plates) or urease activity (tubes). The transport medium, the A-7 agar, and the U-9 medium were prepared by the laboratory.

Specimens for bacteriological cultures were obtained within the first hour of life. The suction catheter was attached to a sterile mucus trap. The specimens were transported to the laboratory within the trap, and cultures were performed using blood and MacConkey agar plates.

After centrifugation of tracheal aspirate samples, the cells were resuspended with 150 ul of $0.9 \%$ saline, and a total white cell count was performed using a haemocytometer. A differential blood count was obtained after Pappenheim staining of a cytocentrifuged cell sample.

Assay of chemotactic activity and assays for C5a and elastase activity were performed as described before. ${ }^{1213}$ Assays for interleukin-1 (Quantikine; R\&D Systems Inc, Minneapolis,
USA, sensitivity $0.3 \mathrm{pg} / \mathrm{ml}$ ), interleukin-8 (Amersham Corporation, Aylesbury, United Kingdom, sensitivity $4.7 \mathrm{pg} / \mathrm{ml}$ ), leukotriene $\mathrm{B}_{4}$ (Amersham Corporation, Aylesbury, United Kingdom, sensitivity $6 \mathrm{pg} / \mathrm{ml}$ ), elastase$\alpha_{1}$-proteinase inhibitor (Merok, Darmstadt, Germany, sensitivity $40 \mathrm{ng} / \mathrm{ml}$ ) were performed according to the manufacturers' instructions.

To avoid errors resulting from the sampling procedure, concentrations of inflammatory mediators measured in TA were related to concentrations of the secretory component as the reference protein. Secretory component concentration in lung effluent fluid is independent of capillary leak and not affected by gestational or postnatal age during the first month of life. ${ }^{14}$ Assays for secretory component were performed, as described before. ${ }^{12}$ Chemotactic activity and numbers of neutrophils in TA were not related to secretory component.

As some of the data were not normally distributed, values were expressed as median (25th-75th percentile) or as median (range). Two group comparisons were performed using the Mann Whitney U test. Significance was accepted at $P<0 \cdot 05$. Demographic data were expressed as mean (SD). Differences in numbers of patients with detectable activity of free elastase in TA were compared between both groups using the $\chi^{2}$ test.

\section{Results}

Mean gestational age and birthweight of all 81 patients was $27 \cdot 9(2 \cdot 0)$ weeks and $945(179) \mathrm{g}$. Ten infants died during the first 10 days. There were four late deaths after day 28 ; overall survival rate was $83 \%$. Microbial colonisation of the airways was present in 12 patients ( $U$ urealyticum $\mathrm{n}=7$, Escherichia coli $\mathrm{n}=4$, Staphylococcus aureus $\mathrm{n}=1$ ); in 69 patients the cultures were negative. Group B streptococci were not isolated during the study period.

No differences were found in gestational age, birthweight, gender, rate of caesarean section or use of prenatal steroids between both groups. Premature rupture of membranes and maternal signs of infection were more often present in neonates with colonised airways (table 1). RDS was diagnosed more often in the non-colonised group than in the

Table 1 Demographic characterisation and outcome data of patients

\begin{tabular}{lll}
\hline & $\begin{array}{l}\text { Colonised } \\
\text { neonates } \\
(n=12)\end{array}$ & $\begin{array}{l}\text { Non-colonised } \\
\text { neonates } \\
(n=69)\end{array}$ \\
\hline Mean (SE) birthweight (g) & $944(55)$ & $948(23)$ \\
Mean (SE) gestational age (weeks) & $27 \cdot 5(0 \cdot 6)$ & $28 \cdot 0(0 \cdot 2)$ \\
Female \% & 50 & 48 \\
Caesarean section \% & 75 & 88 \\
Prenatal steroid \% & 66 & 69 \\
PROM > 24 h \% & $67^{\star \star}$ & 19 \\
Maternal signs of infection \% & $50^{\star}$ & 18 \\
Maternal antibiotics \% & 50 & 21 \\
RDS \% & 25 & 75 \\
BPD \% & 17 & 20 \\
Dexamethasone treatment \% & 41 & 41
\end{tabular}

PROM: premature rupture of membranes; maternal signs of infection include fever $>38^{\circ} \mathrm{C}$ and/or peripheral blood leucocytosis $>20000$ cells $/ \mu \mathrm{l}$. 
Table 2 Chemotactic activity, neutrophil count, concentrations of interleukin-1, leukotriene $B_{4}$, interleukin-8, C5a, elastase- $\alpha_{1}$-proteinase inhibitor, secretory component of $\operatorname{Ig} A$, and numbers of patients with free elastase in tracheal aspirate fluid of infants with microbial colonisation of the airways and non-colonised neonates on day 1 of life

\begin{tabular}{|c|c|c|}
\hline & $\begin{array}{l}\text { Colonised neonates } \\
(n=12)\end{array}$ & $\begin{array}{l}\text { Non-colonised neonates } \\
(n=69)\end{array}$ \\
\hline 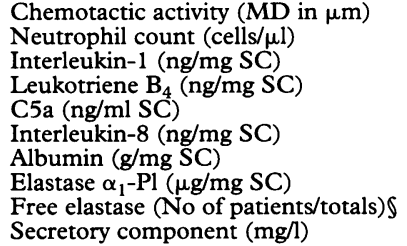 & $\begin{array}{c}146(124-165)^{\star \star} \\
1650(300-5125)^{\star \star} \\
22(17 \cdot 7-39 \cdot 3)^{\star \star} \\
33 \cdot 2(11 \cdot 5-94 \cdot 3)^{\star} \\
319(236-328) \\
1244(645-1746) \\
4 \cdot 2(2 \cdot 0-5 \cdot 6) \\
178(126-311)^{\star} \\
8 / 12^{\star} \\
4 \cdot 8(1 \cdot 2-11 \cdot 0)\end{array}$ & $\begin{array}{l}70(57-96) \\
235(51-539) \\
1 \cdot 0(0-6 \cdot 1) \\
12 \cdot 0(3 \cdot 4-33 \cdot 0) \\
273(147-379) \\
605(245-1325) \\
5 \cdot 3(1 \cdot 3-13 \cdot 5) \\
112(55-201) \\
12 / 69 \\
5 \cdot 3(1 \cdot 3-13 \cdot 5)\end{array}$ \\
\hline
\end{tabular}

$\S$ Numbers of patients with detectable activity of free elastase/total number of patients, all other Numbers of patients with detectable activity of free elastase/total number of patients, all other values: median (25th-75th percentile). Significant differences between the groups are indicate
by $\star P<0.05$, and $\star \star P<0.01$ by ${ }^{\star} \mathrm{P}<0 \cdot 05$, and
exposed to tracheobronchial aspirate fluid. $S C$ : secretory component.

colonised group. In all three infants with perinatal airway colonisation and respiratory distress (suspected neonatal pneumonia) $E$ coli were isolated from the respiratory secretions. It was not possible in these infants to distinguish the chest radiograph from RDS. The rate of $B P D$, and the number of infants treated with dexamethasone, were no different in either group (table 1).

Chemotactic activity, neurophil cell count, and concentrations of $\mathrm{LTB}_{4}, \mathrm{IL}-1, \mathrm{Ea}_{1} \mathrm{PI}$, and number of infants with free elastase in TA were significantly higher in the colonised group compared with non-colonised infants (table 2). The most pronounced difference between both groups was seen in the concentration of IL-1, which was 20 -fold higher in colonised infants. When not related to secretory component, concentrations of IL-1 were $157 \mathrm{ng} / \mathrm{l}$ (108-464), and $3.2 \mathrm{ng} / 1$ (0-14.1), respectively (median 25 th -75 th percentile, $P<0.01$ ) (figure). Eleven of 12 infants with tracheal colonisation had IL1 concentrations exceeding $100 \mathrm{ng} / \mathrm{l}$ in contrast to only three of 69 non-colonised infants (sensitivity $0.92(95 \%$ confidence interval $0.62-1.0)$; specificity $0.96(95 \%$ CI $0.88-0.99)$; positive predictive value 0.79 (95\% CI $0.49-0.95)$; negative predictive value $0.98(95 \%$ CI $0.92-1 \cdot 0)$ ). When corrected for secretory component, IL-1 concentrations of more than $15 \mathrm{ng} / \mathrm{mg}$ had a sensitivity of $0.92(95 \%$ CI $0.62-1.0)$; specificity 0.93 (95\% CI $0.84-0.98)$; positive predictive value $0.69(95 \%$ CI $0.41-0.89)$; negative predictive value $0.98(95 \%$ CI $0.92-1 \cdot 0)$.

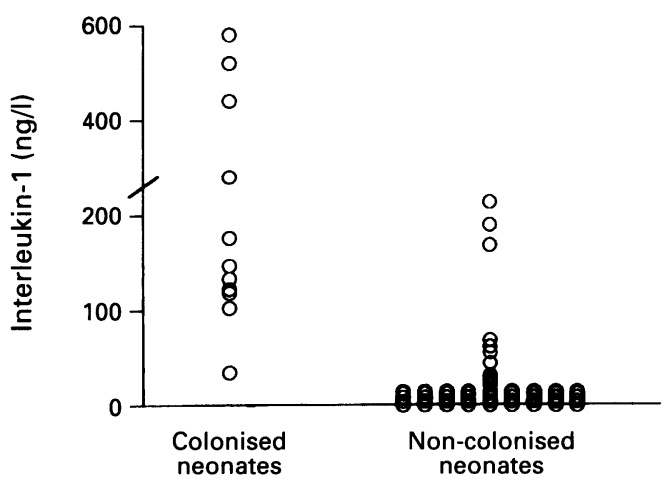

The median of numbers of neutrophils was seven-fold higher in infants with infection, but variability of cell numbers was high in this group. Only infants with colonised tracheobronchial secretions had neutrophil counts exceeding 1500 cells $/ \mu l$. There was a trend towards increased concentrations of IL-8 in respiratory secretions of colonised infants $(P=0 \cdot 07)$. No differences were found between both groups in the concentrations of $\mathrm{C} 5 \mathrm{a}$, and albumin. Additionally, there were no differences in the concentrations of the secretory component for IgA. Within the group colonised with micro-organisms, there were no differences in concentrations of inflammatory indicators between infants colonised with $U$ urealyticum or with bacteria (table 3 ).

\section{Discussion}

In this study preterm infants with positive cultures for bacteria or $U$ urealyticum in airway secretions on the first day of life exhibited a significant inflammatory bronchopulmonary response. Chemotactic activity, numbers of neutrophils, and concentrations of interleukin1, leukotriene $\mathrm{B}_{4}$, and $\mathrm{Ea}_{1} \mathrm{PI}$ were increased in tracheobronchial secretions compared with non-colonised neonates.

IL-1 is one of the most important cytokines regulating the inflammatory response. ${ }^{15}$ It is released locally by alveolar macrophages after stimulation with bacterial toxins or during phagocytosis of micro-organisms. In animal models intratracheal instillation of endotoxin induces an intra-alveolar inflammatory reaction composed of a neutrophilic exudate peaking at 6-12 hours, a monocytic exudate peaking at 24 hours, and a lymphocyte exudate that peaked at 48 hours. The kinetics and magnitude of this sequence were reproduced by intratracheal injection of $\mathrm{IL}-1^{16}$ and blocked by IL-1-receptor antagonist. ${ }^{17} \mathrm{Gram}$ positive bacteria initiate macrophage activation by lipoteichoic acid. ${ }^{18}$ The mechanism of macrophage activation by micro-organisms without a cell wall, such as $U$ urealyticum, has not been identified yet. In children with bacterial pulmonary infections increased IL-1 concentrations are found in bronchoalveolar washings. ${ }^{19}$ Our study also pinpointed substantially increased concentrations of IL-1 in

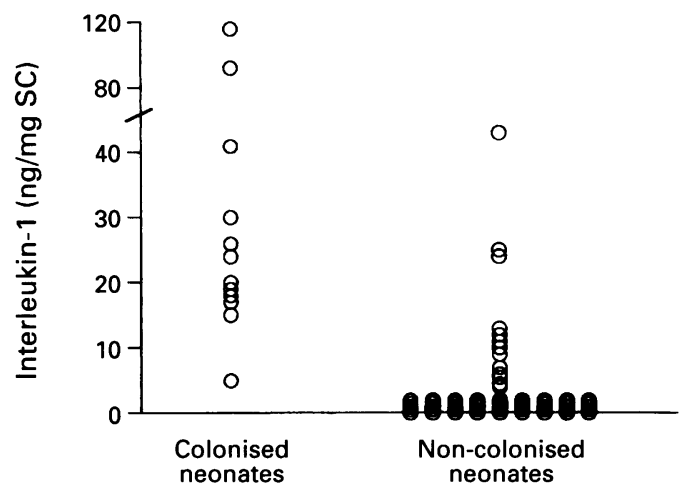


Table 3 Chemotactic activity, neutrophil count, concentrations of interleukin-1, leukotriene $B_{4}$, interleukin-8, C5a, elastase- $\alpha_{1}-$ proteinase inhibitor, and numbers of patients with free elastase in tracheal aspirate fluid of infants colonised with $\mathrm{U}$ urealyticum vs bacterial colonisation on the first day of life

\begin{tabular}{lcc}
\hline & $\begin{array}{c}\text { Colonisation with } \\
\text { U urealyticum }(n=7)\end{array}$ & $\begin{array}{c}\text { Bacterial colonisation } \\
(n=5)\end{array}$ \\
\hline Chemotactic activity (MD in $\mu \mathrm{m})$ & $141(93-168)$ & $159(125-197)$ \\
Neutrophil count (cells/ $\mu$ ) & $900(770-3500)$ & $1350(200-24600)$ \\
Interleukin-1 (ng/mg SC) & $25 \cdot 9(17 \cdot 5-119)$ & $19 \cdot 5(5 \cdot 5-93)$ \\
Leukotriene B $_{4}(\mathrm{ng} / \mathrm{mg} \mathrm{SC})$ & $31 \cdot 5(16 \cdot 3-187)$ & $11(6 \cdot 5-78)$ \\
C5a (ng/mg SC) & $288(72-721)$ & $338(134-645)$ \\
Interleukin-8 (ng/mg SC) & $1721(569-2760)$ & $1579(160-3977)$ \\
Elastase $\alpha_{1}-\mathrm{Pl}(\mu \mathrm{g} / \mathrm{mg} \mathrm{SC)}$ & $222(133-720)$ & $190(88-470)$ \\
Free elastase (No of patients/totals) & $5 / 7$ & $3 / 5$ \\
\hline
\end{tabular}

Snumber of patients with detectable activity of free elastase/total number of patients, all other values: median (range). MD means miratory distance of peripheral blood neutrophils exposed to tracheobronchial aspirate fluid. SC: secretory component.

the TA of infants with growth of bacteria or $U$ urealyticum. IL-1 concentrations in TA exceeding $100 \mathrm{ng} / \mathrm{l}$ may be a diagnostic marker for local microbial airway colonisation. However, there were no differences in IL-1 concentrations between infected infants with clinical signs of respiratory distress (suspected neonatal pneumonia), and infants with a positive culture but without respiratory disease. Thus IL-1 concentrations in pulmonary effluent fluid do not differentiate between a local host response towards tracheal colonisation or pneumonia.

Following stimulation by microbial products, as well as during phagocytosis of microorganisms, macrophages release factors that recruit neutrophils. Chemotactic activity of TA towards neutrophils was significantly increased in infants with colonised airways compared with non-colonised infants. Increased chemotactic activity of bronchoalveolar fluid together with increased concentrations of $\mathrm{LTB}_{4}$ and C5a have also been found in adults with pneumonia. ${ }^{20}$ The generation of $\mathrm{C} 5 \mathrm{a}$ as well as IL-8 was increased in the respiratory fluid of infants with cystic fibrosis and Pseudomonas aeruginosa colonisation. ${ }^{2122}$ In adults with chronic airway disease the neutrophil chemotactic activity of bronchoalveolar lavage was related to $\mathrm{LTB}_{4}, \mathrm{C} 5 \mathrm{a}$, and IL-8. ${ }^{23}$ Increased concentrations of IL-8 were found in the airway secretions of ventilated patients during the development of nosocomial pneumonia. ${ }^{2425}$ Fibroblasts infected with $U$ urealyticum in vitro secrete large amounts of IL-8. ${ }^{26}$ In our study $\mathrm{LTB}_{4}$ concentrations were fourfold higher in TA colonised with micro-organisms than in infants with sterile lung effluent. High $\mathrm{LTB}_{4}$ concentrations indicate that this mediator is an important chemoattractant in local microbial infection. The source of $\mathrm{LTB}_{4}$ may be macrophages or the neutrophils themselves. However, $U$ urealyticum produces phospholipase $A$ and $C$, which can catalyse the release of arachidonic acid, the precursor of $\mathrm{LTB}_{4}$, from membrane phospholipid stores. ${ }^{27}$ In contrast to $\mathrm{LTB}_{4}$ concentrations, those of IL-8 were only slightly higher in colonised neonates compared with the non-colonised group, and there was no difference for C5a. These chemoattractants may also be generated in larger amounts within the airways following other stimuli like barotrauma or oxygen toxicity during mechanical ventilation for RDS. ${ }^{28}$
As a result of increased chemotactic activity of respiratory fluids neutrophils are attracted into the airways. In our study neutrophil count was higher in TA with perinatal colonisation. This has been described by others. ${ }^{5-7}$ Activated neutrophils release elastase, which is bound by $\alpha_{1}$-proteinase inhibitor and antileucoprotease present in the respiratory fluid. In this study elastase- $\alpha_{1}$-proteinase inhibitor concentrations were significantly higher in infants with colonised secretions than in infants with sterile airway fluid. Free elastase was also more frequently present in the TA of infants with airway colonisation. Increased amounts of elastase $\alpha_{1}$-proteinase inhibitor have been found in the tracheal secretions of newborns with bacterial airway colonisation. ${ }^{29}$ In half of the patients with pneumonia free functional extracellular elastase was found that was not bound to $\alpha_{1}$-proteinase inhibitor. ${ }^{30}$ Additionally, free elastase was detected in the TA of patients with cystic fibrosis and colonisation with Pseudomonas aeruginosa, ${ }^{21}$ and in long term ventilated infants with BPD and nosocomial airway infection. ${ }^{31}$ The presence of free elastase in TA has been associated with increased early respiratory morbidity in preterm infants with RDS. ${ }^{32}$

Increased concentrations of inflammatory mediators have also been found in tracheal secretions of infants with BPD. ${ }^{12}{ }^{33}$ During the development of this disease, airway inflammation did not seem to be related to infection, but rather, to unspecific lung injury from oxygen toxicity and barotrauma. The concentrations of mediators in TA were lower than those found in infected secretions studied here. ${ }^{13}$ In another study airway infection at birth was associated with the development of WilsonMikity syndrome. ${ }^{10}$ The impact of microbial colonisation of the airways during mechanical ventilation on the development of neonatal chronic lung diseases should be evaluated in further studies.

In conclusion, this study has shown that preterm infants with positive cultures for bacteria or $U$ urealyticum in airway secretions on the first day of life exhibit a significant inflammatory bronchopulmonary response, with evidence for local macrophage activation, neutrophil recruitment into the airways, and increased secretion of neutrophil products. However, as not all of these infants had respiratory symptoms, the results do not allow us to distinguish between a local host response against colonisation and bronchopulmonary infection. An increased concentration of interleukin-1 in the TA on the first day of life may be a marker of perinatal colonisation of the airways.

Supported by a grant from Deutsche Forschungsgemeinschaft (Sp 239/4-1).

1 Webber S, Wilkinson D, Lindsell D, Hope PL, Dobson SRM, Isaacs D. Neonatal pneumonia. Arch Dis Child 1990; 65: 207-11.

2 Cassell GH, Waites KB, Crouse DT, et al. Association of Ureaplasma urealyticum infection in the lower respiratory ract with chronic birthweight infants. Lancet 1988; ii: $240-5$.

3 Wang EE, Cassell GH, Sanchez PJ, Regan JA, Payne NR, Liu PP. Ureaplasma urealyticum and chronic lung disease: critical appraisal of the literature on causation. Clin Infect Dis 1993; 17 (suppl 1): S112-16. 
4 Holtzman RB, Hageman JR, Yogev R. Role of Ureaplasma urealyticum in bronchopulmonary dysplasia. $\mathcal{F}$ Pediatr 1989; 114: 1061-3.

5 Sherman MP, Goetzman BW, Ahifors CE, Wennberg RP. Tracheal aspiration and its clinical correlates in the diag nosis of congenital pneumonia. Pediatrics 1980; 65: 258-63.

6 Arnon S, Grigg J, Silverman M. Association between pulmonary and gastric inflammatory cells on the first day of life in preterm infants. Pediatr Pulmonol 1991; 16: 59-61.

7 Payne NR, Steinberg SS, Ackerman P, Chrenka BA, Sane $\mathrm{SM}$, Anderson KT, et al. New prospective studies of the association of Ureaplasma urealyticum colonization and chronic lung disease. Clin Infect Dis 1993; 17 (suppl 1): chronic lung

8 Grigg J, Arnon S, Chase A, Silverman M. Inflammatory cells in the lungs of premature infants on the first day of life: perinatal risk factors and origin of cells. Arch Dis Child 1993; 69: 40-3.

9 Grigg J, Barber A, Silverman M. Increased levels of bronchoalveolar fluid interleukin-6 in preterm ventilated infants after prolonged rupture of membranes. Am Rev Respir Dis 1992; 45: 782-6.

10 Fujimura $M$, Kitajima $H$, Nakayama $M$. Increased leucocyte elastase of the tracheal aspirate at birth and neonatal pulmonary emphysema. Pediatrics 1993; 92: 564-9.

11 Speer CP, Robertson B, Cursted T, Halliday $H$ Compagnone D, Gefeller O, et al. Randomized European multicenter trial of surfactant therapy for severe neonatal multicenter trial of surfactant therapy for severe neonatal respiratory distress syndrome: single vers

12 Groneck P, Goetze-Speer B, Oppermann M, Eiffert $H$ Speer CP. Association of pulmonary inflammation and increased microvascular permeability during the development of bronchopulmonary dysplasia: a sequential analysis of inflammatory mediators in respiratory fluids of high risk preterm infants. Pediatrics 1994; 93: 712-18.

13 Groneck P, Reuss D, Goetze-Speer B, Speer CP. Effects of dexamethasone on chemotactic activity and inflammatory mediators in tracheobronchial aspirates of preterm infants at risk for chronic lung disease. $\mathcal{f}$ Pediatr 1993; 122: 938-44.

14 Watts CL, Fanaroff M, Bruce MC. Elevation of fibronectin levels in lung secretions of infants with respiratory distress syndrome and development of bronchopulmonary dysplasia. F Pediatrics 1992; 120: 614-20.

15 Dinarello CA. Cytokines: interleukin-1 and tumor necrosis factor. In: Gallin JI, Goldstein IM, Synderman R, eds Inflammation, basic principles and clinical correlates. New York: Raven Press, 1988: 195-208.

16 Ulich TR, Watson LR, Yin S, Guo K, Wang P, Thang H, et al. The intratracheal administration of endotoxin and cytokines. I. Characterisation of IPS-induced II- 1 and TNF mRNA expression and the LPS-, IL-1-, and TNF induced inflammatory exsudate. Am F Pathol 1991; 138: induced infle

17 Ulich TR, Yin S, Guo K, delCastillo J, Eisenberg SP, Thompson RC. The intratracheal administration of endotoxin and cytokines. III. The interleukin-1 receptor antagonist inhibits endotoxin- and IL-1 induced acute inflammation. Am f Pathol 1991; 138: 521-4.

18 Standiford TJ, Arenberg DA, Danforth JM, Kunkel SL, Van Otteren GM, Strieter RM. Lipoteichoic acid induces secretion of interleukin-8 from human blood monocytes: a cellular and molecular analysis. Infect Immunol 1994; 62. 119-25.

19 Wilmott RW, Kassab JT, Kilian PL, Benjamin WR, Douglas $S D$, Wood RE. Increased levels of interleukin-1 in bron choalveolar washings from children with bacterial pulmonary infections. Am Rev Respir Dis 1990; 142: 365-8.

20 Hopkins H, Stull T, von Essen SG, Robbins RA, Rennard SI. Neutrophil chemotactic factors in bacterial pneumonia. Chest 1989; 95: 1021-7.

21 Fick RB, Robbins RA, Squier SU, Schoderbek WE, Russ WD. Complement activation in cystic fibrosis respiratory fluids: in vivo and in vitro generation of $\mathrm{C} 5 \mathrm{a}$ and chemotactic activity. Ped Res 1986; 20: 1258-68.

22 Massion PP, Inoue H, Richman-Eisenstad J, Grunberger D, Jorens PG, Housset B, et al. Novel Pseudomonas product stimulates interleukin-8 production in airway epithelia cells in vitro. F Clin Invest 1994; 93: 26-32.

23 Ozaki T, Hayashi H, Tani K, Ogushi F, Yasuoka S, Ogura $T$. Neutophil chemotactic factors in the respiratory trac of patients with chronic airway diseases of idiopathic pulmonary fibrosis. Am Rev Respir Dis 1992; 145: 85-91.

24 Rodriguez JL, Miller CG, DeForge LE, Kelty L, Shanley CJ, Bartlett RH, et al. Local production of interleukin-8 is associated with nosocomial pneumonia. F Trauma 1992; 33: 74-82.

25 Chollet-Martin S, Montravers $P$, Gilbert C, Elbim C Desmonds JM, Fagon JY, et al. High levels of interleukin8 in the blood and alveolar spaces of patients with pneu8 in the blood and alveolar spaces of patients with pneumonia and adult respiratory

26 Stancombe BB, Walsh WF, Derdak SD, Dixon P, Hensley $D$. Induction of human neonatal pulmonary fibroblas cytokines by hyperoxia and ureaplasma urealyticum. Clin Infect Dis 1993; 17 (suppl 1): S154-7.

27 De Silva NS, Quinn PA. Endogenous activity of phospholipases $A$ and $C$ in Ureaplasma urealyticum. $\mathcal{f}$ Clin Microbiol 1986; 23: 354-9.

28 De Forge LE, Preston AM, Takeuchi E, Kenney J, Boxer LA, Remick DG. Regulation of interleukin-8 gene expression by oxidant stress. 7 Biol Chem 1993; 268: 25568-76.

29 Tegtmeyer FK, Maaks S, Wood G, Wiebicke W. Elastase $\alpha_{1}$-proteinase inhibitor and lactoferrin concentrations in $\alpha_{1}$-proteinase inhibitor and lactoferrin concentrations in Pulmonol 1992; 13: 90-4.

30 Abrams WR, Fein AM, Kucich U, Kueppers F, Yamada H, Kuzmowycz $\mathrm{T}$, et al. Proteinase inhibitory function in inflammatory lung disease. Am Rev Respir Dis 1984; 129: 735-41.

31 Walti H, Tordet C, Gerbaut L, Saugier P, Moriette G Relier JP. Persistent elastase/proteinase inhibitor imbalance during prolonged ventilation of infants with bronchopulmonary dysplasia: evidence for the role of nosocomial infections. Ped Res 1989; 26: 351-5.

32 Speer CP, Reuss D, Harms K, Herting E, Gefeller O Neutrophil elastase and acute pulmonary damage in infants with severe respiratory distress syndrome Pediatrics 1993; 91: 794-9.

33 Kotecha S, Chan B, Azam N, Silverman M, Shaw R. Increase in interleukin-8 and soluble intercellular adhesion molecule-1 in bronchoalveolar lavage fluid from premature infants who develop chronic lung disease. Arch Dis Child 1995; 72: F90-6. 